\title{
AC 2010-20: USE OF LEARNING STYLES FOR TEAMWORK AND PROFESSIONAL DEVELOPMENT IN A MULTIDISCIPLINARY COURSE
}

Eli Patten, University of California at Berkeley

Sara Atwood, University of California, Berkeley

Lisa Pruitt, University of California, Berkeley 


\title{
Use of Learning Styles for Teamwork and Professional Development in a Multidisciplinary Course
}

\begin{abstract}
With the rise of integrated fields of study in engineering such as energy, biotechnology and robotics, graduating engineering students must be able to communicate effectively in teams from a variety of backgrounds. In fact, ABET has specifically identified these skills as criteria $3 \mathrm{~d}$ and 3g. Particularly in multidisciplinary fields, engineers have different motivations, technical backgrounds, and ways of learning. In the undergraduate classroom, students can develop skills to communicate with their multidisciplinary team members and other audiences by taking into account the variety of learning styles and backgrounds. Felder et. al. ${ }^{1}$ developed a classification of learning styles in which individuals' natural tendencies fall on a continuum in four categories: visual-verbal, sensing-intuitive, global-sequential, and active-reflective. We used this learning style classification as a framework to incorporate teamwork and professional development into a multidisciplinary course.
\end{abstract}

Structural Aspects of Biomaterials is an upper-level undergraduate course cross-listed with mechanical and bio- engineering. Enrollment is about 50 students with a near even gender split. In addition to weekly, case-based lectures, there is a required professional development lab. In the lab, students identified their learning styles with Felder's online assessment tool. ${ }^{2}$ Learning styles are discussed explicitly and incorporated into lectures, exams, assignments, and a teambased project. For the final course project, teams of about four students were assigned so that all majors, learning styles, and genders were represented in each team. The final project included an oral presentation, a written report, and an outreach teaching activity at a local children's science museum. The lab was assessed using four surveys throughout the semester.

Most students reported noticing how different learning styles contributed to group discussions (70\%) and thought it brought new and creative ideas to their teams (50\%). On average, female students ranked learning styles, teamwork, and the outreach teaching activity as more useful for this course, other courses, and their career while male students ranked Bloom's taxonomy and literature search activities as more useful. With respect to different majors, bioengineers ranked technical writing, oral presentations, and teamwork as more useful, while mechanical engineers ranked the literature search activities as more useful. This indicates that various activities engaged students of different backgrounds and genders while promoting teamwork and professional development skills. When students assessed their confidence in communication and teamwork, the average confidence improved from 3.1 at the beginning of the course to 4.0 at the end (1-5 scale). Furthermore, the student ranking of the usefulness of the course on department surveys was 5.8 out of 7 . This learning styles framework can be adapted for other multidisciplinary courses that want to address the student challenges of communicating effectively and functioning on multidisciplinary teams.

\section{Introduction}

Multidisciplinary courses have become increasingly popular, and are concomitant with the growth of interdisciplinary fields such as bioengineering, MEMS, and energy and sustainability. The number of papers published on engineering education in multidisciplinary areas has also increased in the past several years. Further, multidisciplinary courses can address two main 
ABET program outcome criteria: 3d) an ability to function on multidisciplinary teams, and $3 \mathrm{~g}$ ) an ability to communicate effectively. ${ }^{3}$

Designing and teaching a multidisciplinary course can be challenging for many reasons. The primary and most obvious challenge is the difference in the technical background of the students. This is not just a challenge in a lecture, but also when students are working on projects with group members from different backgrounds and need to communicate with one another. A secondary challenge is the variety of learning styles present in any course, especially in a multidisciplinary one. The particular learning style of a student may affect not only how they learn, but also how they teach and communicate.

If the students are aware of their own learning style and know how to effectively communicate with people of different learning styles, then they would be better able to work on multidisciplinary and diverse teams. To gain experience working on a team with diverse learning styles, students can be arranged in groups based on their background and the results of a learning style assessment. When Halstead and Martin let students choose between a self-selected group and a group selected based on learning style diversity, the students in groups based on learning styles performed at a higher level than the students in self-selected groups ${ }^{4}$ and Wilde has reported that the performance of student design teams improves when they are arranged using guidance from a Myers-Briggs Type Indicator and the students pay attention to their individual personalities. ${ }^{5}$ In this paper we describe how we integrated learning styles into a skills lab for an upper-level engineering course cross-listed in bioengineering and mechanical engineering.

A well-known and simple model for learning and teaching styles is the one developed by Felder and Silverman. ${ }^{1,6}$ This model classifies the preferred learning style of a student along a continuum within four categories: perception (sensory or intuitive), input (visual or verbal), processing (active or reflective), and understanding (sequential or global). Sensory learners focus on external inputs (see, hear, touch, etc.) and tend to be practical and prefer facts, data, and experimentation. Intuitive learners focus on internal inputs (thoughts, memories, images, etc.), and tend to be imaginative and prefer principles, theories, and models. Visual learners tend to remember what they see (pictures, charts, diagrams, etc.), while verbal learners tend to remember what they hear and read. Active learners learn best when doing active experimentation or discussion and prefer group work. Reflective learners like to observe experiments, think about information introspectively, and prefer individual assignments. Sequential learners like to have information presented in a linear fashion, with each new idea building off of previously learned information. Global learners need to understand how all of the information relates to each other before they can understand the details and like to jump directly into complex material to understand the material all at once. Students can exhibit tendencies on both sides of each continuum, but usually have a preferred style. The Index of Learning Styles is a free, online questionnaire designed to assess preferences in these four dimensions of learning styles. ${ }^{2}$ The index is widely used and has been shown to have good reliability and validity.,8,9

\section{Course Structure/Design}

Structural Aspects of Biomaterials is an upper-level elective course listed in both the mechanical and bioengineering departments at a large public research university. Topics include material properties, mechanical behavior, and clinical significance of the biological tissues, metals, 
ceramics, and polymers used in medical devices. The FDA, patent law, and ethical considerations are also part of the course material.

The course enrollment is typically about 50 students with a relatively even split amongst genders and majors. This particular year the enrollment was 48 students: 23 female, 25 male; 15 students from mechanical engineering (ME), 31 from bioengineering (BE), 6 from material science engineering (MSE), 2 from electrical and computer science engineers (EECS), and 1 from chemistry. Seven students were double majors in two of these areas. (Note: for reporting the survey results throughout the rest of the paper, we categorized students as either BE or ME; most double majors were either BE or ME combined with another major, usually MSE; the one student that was both BE and ME and the students that were neither BE nor ME were both categorized as ME students.) There were 42 juniors and seniors and 6 graduate students enrolled in the course.

The semester-long course is taught with two 90-minute lectures each week covering the fundamental mechanical and biological course material through traditional lectures, in-class activities, guest lectures, and case studies. In addition, students were required to attend a "professional skills" lab for two hours once a week covering a limited review of mechanics, learning styles, group dynamics, outreach teaching, Bloom's taxonomy ${ }^{10}$, assessment rubrics, library skills, technical writing and editing, and oral presentations (Table 1). Students were assessed based on two midterm exams and a final group project comprising a written report, an oral presentation, and an outreach teaching activity at a local children's science museum. There was one professor in change of presenting lectures and two graduate students in charge of the lab, with no extra graders.

Table 1: Descriptions of the main skills labs

Mechanics review: Refresher for basic mechanics of materials, covering free-body-diagrams, bending stress, etc; involves examples and group activities and presentations

Learning styles: $\quad$ Introduced and discussed learning styles; class activity (see text)

Team building: Students were organized into their groups for the first time; group design activity building a gliding device using paper, tape, and a straw

Bloom's taxonomy: Bloom's taxonomy of learning objectives is introduced and discussed; class activity

Library workshop: Students learned about the resources available for finding scholarly information in the bioengineering fields and how to search for journal articles; facilitated by library staff

Technical writing: $\quad$ Presented the basic ideas for strong technical writing; examples and class activities

Oral presentation: Presented the basic ideas for strong technical oral presentations

Editing writing: Groups traded drafts of their papers and peer evaluated them

Exhibit feedback: Feedback on the students' ideas for their exhibit from staff of the science museum

Group work: The students worked on the final project in groups throughout the semester 
At the beginning of the course, the students' demographic information was collected: gender, major(s), year in school, relevant course work, and the results of the online learning styles assessment. The learning style assessment gave the students a numeric indicator for their learning preference in each category, over a range from -11 (extreme to one side), to +11 (extreme to the other side). Using this information the course and lab instructors assigned eleven groups with 3-5 students in each. Groups were assigned such that they had a roughly equal representation of gender and majors and had an "average" learning style for each group that was balanced within each of the four categories. We did not mix undergraduate and graduate students. It was obviously impossible to perfectly mix the groups, but the average learning style of each group was usually within several points of the class average (Table 2) and no groups were comprised of students of all the same gender or major.

Table 2: Example of distribution in a typical group. A negative learning style indicator means they prefer the "left" style of that category (active, sensing, visual, or sequential).

\begin{tabular}{cccccccc}
\hline Individual & Major & Year & Gender & Act:Ref & Sen:Int & Vis:Ver & Seq:Glo \\
\hline 1 & $\mathrm{BE}$ & 3 & $\mathrm{~F}$ & 1 & -7 & -7 & 1 \\
2 & $\mathrm{BE}$ & 4 & $\mathrm{M}$ & 5 & 1 & -7 & -3 \\
3 & $\mathrm{BE}$ & 4 & $\mathrm{M}$ & -1 & 9 & -9 & 5 \\
4 & $\mathrm{ME}$ & 3 & $\mathrm{~F}$ & -3 & -5 & -9 & -3 \\
\hline Group average & $3: 1$ & $1: 1$ & $1: 1$ & 0.5 & -0.5 & -8 & 0 \\
Class average & $\sim 2: 1$ & $\sim 1: 1$ & $\sim 1: 1$ & -2.1 & -0.8 & -5.5 & -0.9 \\
\hline
\end{tabular}

One of the early skills labs in the course introduced the Felder-Silverman learning style model and explained the differences between the styles. We also gave examples of how to considering each style when teaching and how the students can best help themselves using study techniques based on their learning method. Then they completed a learning activity in their groups, where each group was assigned a learning style dimension and choose a simple example task (such as playing tic-tac-toe or tying shoelaces). Each group then demonstrated how to best teach that concept to each side of that learning style dimension. Learning styles were continually incorporated throughout the rest of the course as well. For example, when the students were designing their science exhibit and preparing their oral presentations, we strongly encouraged them to include something for both sides of each learning style category.

\section{Assessment}

The success of the skills lab and the course was assessed using four surveys evenly spaced throughout the semester (at the beginning, end, and after each of the two exams). The students gave informed consent to participate in the surveys at the beginning of the semester and used an anonymous code so that we could track individual answers over time without knowing the identity of the students. Protocols for the informed consent and data collection were approved by the campus Committee of Protection of Human Subjects. These surveys were also used to determine if any changes or adjustments were necessary during the course. To encourage the students to fill out the surveys completely and accurately, we presented summaries of the results for each survey and discussed them with the class to show the students to know we were actually interested in their feedback. 
Each survey asked questions about the usefulness of the skills lab activities and their group functionality. For assessing the skills lab activities, students ranked the ten activities based on how useful they were for this course, how useful they think the activities will be for other courses, and how useful they think the activities will be for their career.

To assess how the different learning styles influenced group dynamics, we asked them to check any of the following statements that applied:

a) Having opposing learning styles brings new and creative ideas to our discussions

b) Having opposing learning styles has hindered our discussions

c) The opposing learning styles makes it difficult to work together effectively and come to agreement

d) I can recognize our different learning styles and how it plays into our group discussions

e) I haven't noticed a difference among my group members in terms of how they learn or contribute ideas.

To assess how well the students thought they had achieved the learning objectives of the course, we asked them to rate their confidence, on a scale of 1-5, for the following learning objectives, both before the course and after the course:

a) Operate and communicate effectively on a multi-disciplinary team with a variety of learning and personality styles

b) Effectively communicate technical information in written and oral settings

c) Critically evaluate the written, oral, and engineering analysis work of themselves and others by identifying the strengths and areas for improvement

d) Assess the value of work from various sources such as the internet and peer reviewed journals

e) Describe the importance of engaging the community in a discussion of science through outreach

f) Create a museum exhibit to demonstrate a complex engineering concept to non-technical audience with various learning styles

g) Identify your dominant learning style and develop strategies for enhancing skills in the other learning styles

h) Adapt your teaching and communication to address multiple learning styles

i) Identify levels of Bloom's taxonomy in HW and test questions and in project deliverables

j) Evaluate biomechanical designs within realistic constraints such as economic, environmental, social, political, ethical, health and safety, and manufacturability 
k) Recognize contemporary and historic bioengineering issues and technological advances, and their impact in a global, economic, environmental, and societal context

\section{Results}

Overall, we think the groups performed very well. Their final projects were creative and of high quality. On average, the class was highly visual, mostly active, and slightly sensing and sequential, (Figure 1). This is comparable to what has been found in other studies, ${ }^{8,11-15}$ although the students in this study were slightly more active and slightly less sensing. The bioengineering students and mechanical engineering students displayed similar learning styles.
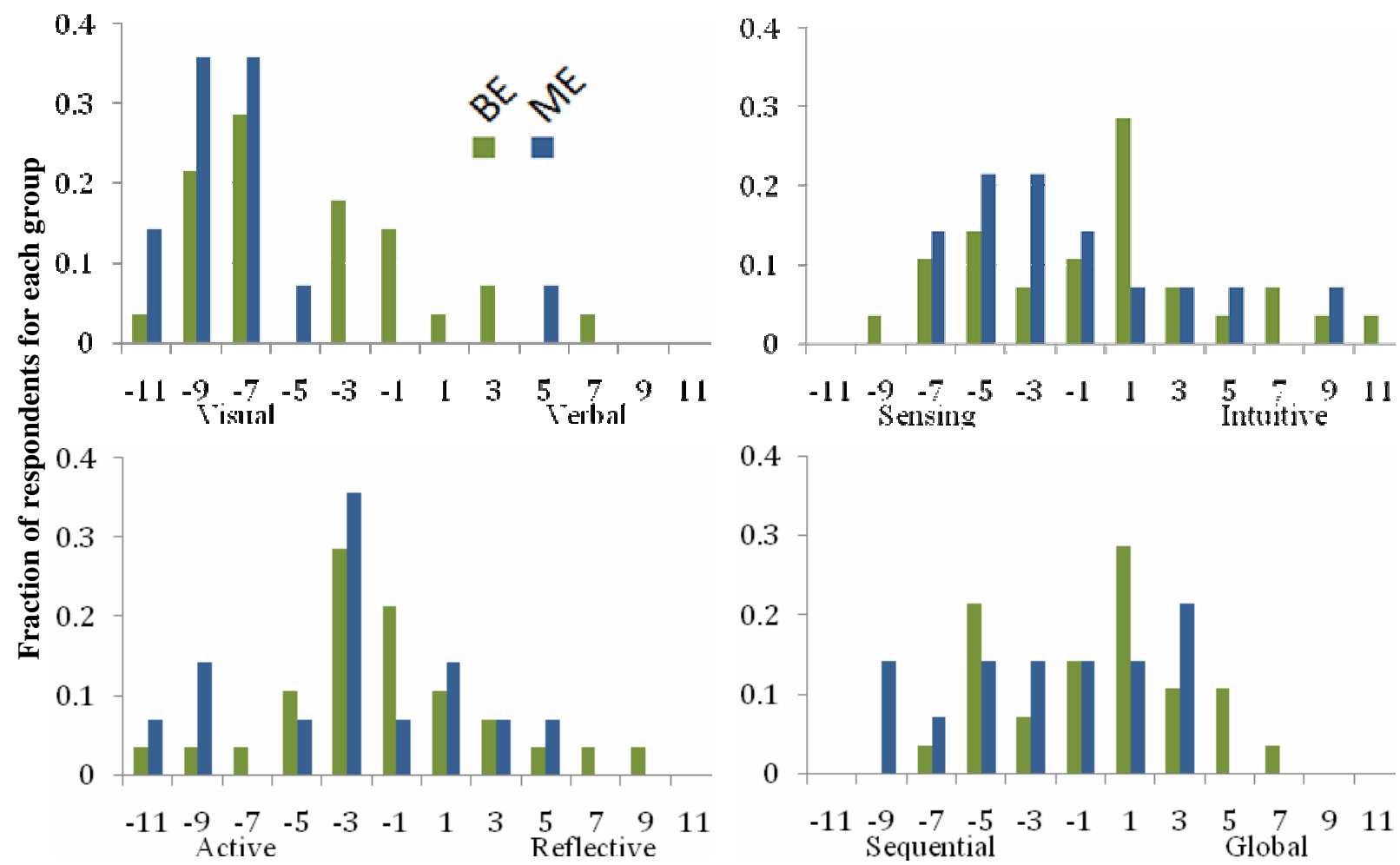

Figure 1: The results of the index of learning styles for the students in the course. $\mathrm{N}=30 \mathrm{BE}$ students and 18 ME students.

Although the class represented a wide range in learning styles, the first and second surveys reported that the students hadn't noticed many differences of learning styles among their group members (27 out of 48) (Figure 2). However, this is likely because the students worked on the majority of their final project closer to the end of the course. For the final survey, only 9 out of 48 students reported not noticing a difference. For the final survey, about $20 \%$ of the students reported that opposing learning styles in the groups hindered their discussion and made it difficult to work together, while $40 \%$ of the students thought that opposing learning styles brought new and creative ideas to their discussion.

The other unique aspect of this class was the skills lab. Both ME and BE students thought that the mechanics review and the group work for the final project were the most helpful aspects of the skills lab for this course, while they thought the Bloom's taxonomy lab and the library workshop were the least useful (Figure 3). For their career, the students thought the technical 
writing, oral presentations, and learning styles would be the most helpful. In general, the bioengineering students thought the technical communication labs (technical writing, oral presentation, and editing writing) were more helpful than the mechanical engineering students did. The mechanical engineers thought the library workshop and the team building activity were more useful.

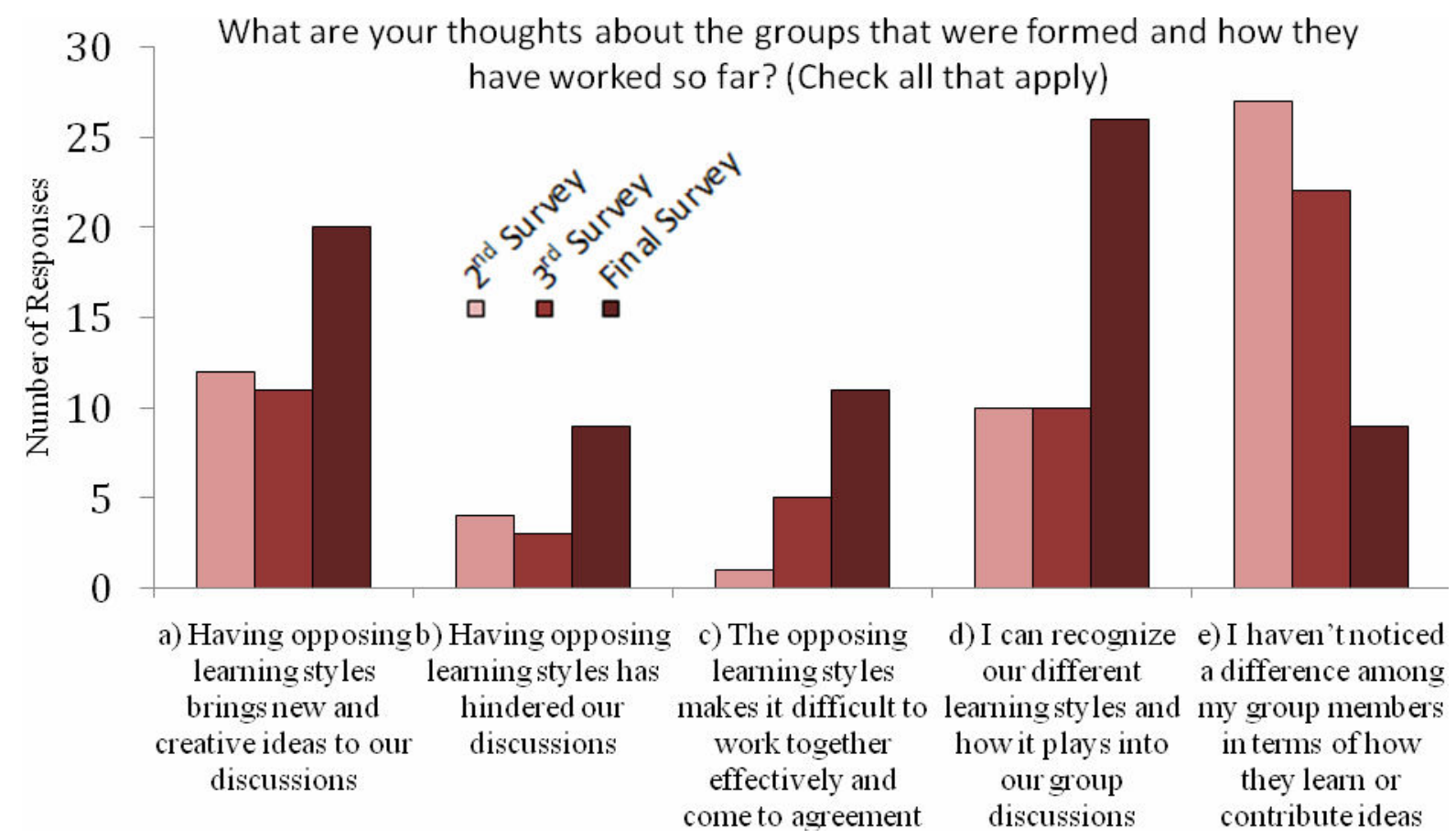

Figure 2: Students' thoughts on how learning styles affected group dynamics. $\mathrm{N}=48$ students for each survey. This question was not asked on the first survey. 


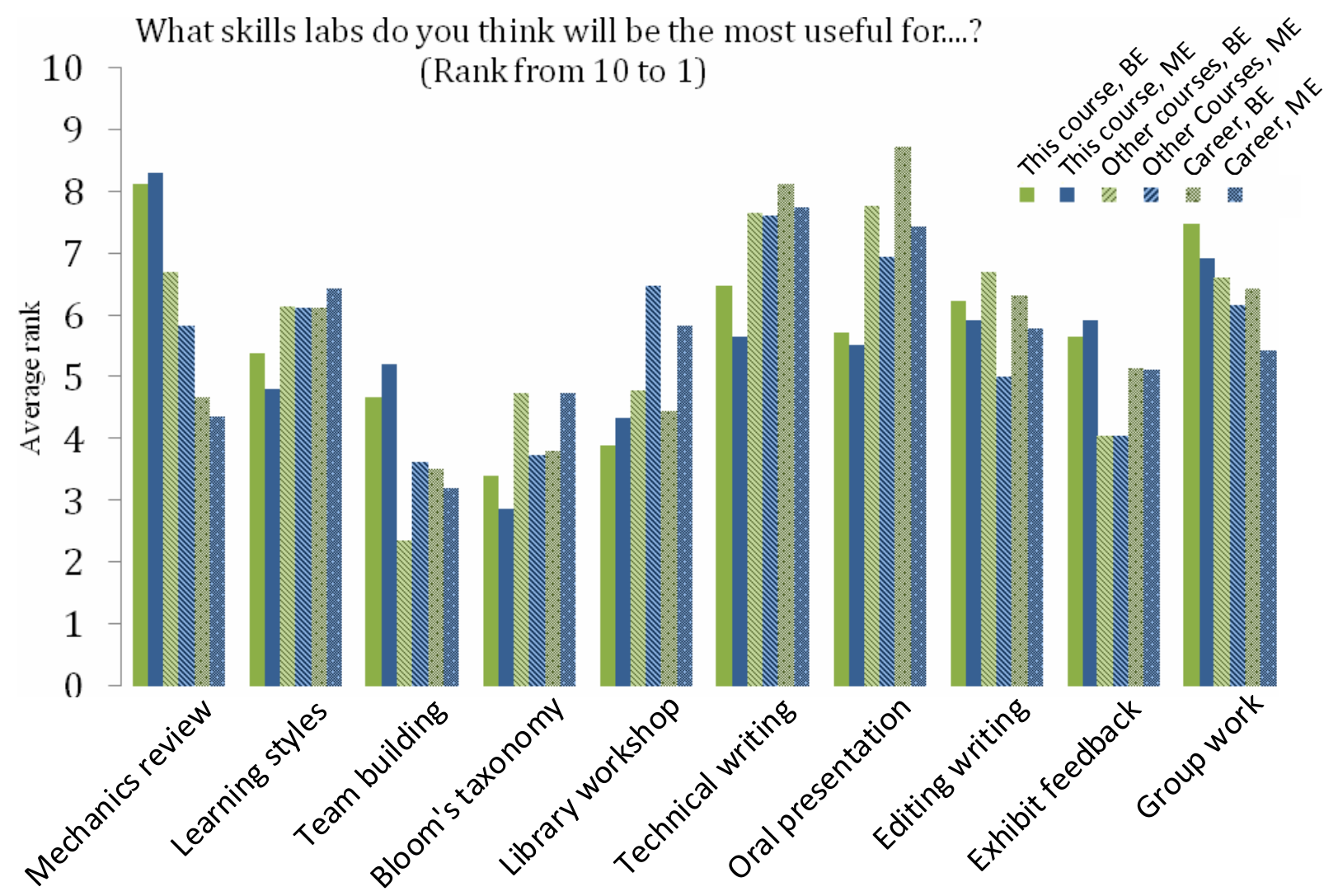

Figure 3: The skills lab that the students found most useful (10 is the most useful). $\mathrm{N}=30 \mathrm{BE}$ students and $18 \mathrm{ME}$ students.

On average, the students reported improving in all the learning objectives from the beginning of the class to the end (Figure 4). The largest improvements were in "evaluating biomechanical designs...," "recognize contemporary and history bioengineering issues...," and "create a museum exhibit..." The smallest improvements were in "assessing the value of work..." and "effective technical communication," although these were some of the highest at the beginning of the course. At the beginning of the course, bioengineering students reported higher levels of confidence than the mechanical engineering students in many areas, including "recognize contemporary and history bioengineering issues...," "Indentify...Bloom's taxonomy...," and "Adapt...to address multiple learning styles." However, by the end of the course both mechanical engineering and bioengineering students reported similar confidence in almost all areas. The small differences among disciplines in terms of what skills labs they thought were important and their final confidence scores demonstrates that the skills lab were able to address the diverse needs of both majors. 
How confident are you in the following areas?

( 5 = very confident)

Recognize contemporary and historic bioengineering issues and technological advances, and their impact in a global, economic, environmental, and societal context

Evaluate biomechanical designs within realistic constraints such as

economic, environmental, social, political, ethical, health...

Identify levels of Blooms taxonomy in HW and test questions and in project deliverables

Adapt your teaching and communication to address multiple learning syles

Identify your dominant learning style and develop strategies for enhancing skills in the other learning styles

Create a museum exhibit to demonstrate a complex engineering concept to non-technical audience with various learning styles

Describe the importance of engageing the community in a discussion of science through outreach

Assess the value of work from various sources such as the internet and peer reviewed journals

Critically evaluate the written, oral, and engineering analysis work of themselves and others by identifying the strengths and areas for improvement

Effectively communicate technical information in written and oral settings

Operate and communicate effectively on a multidisciplinary team witih a variety of learning and personality styles

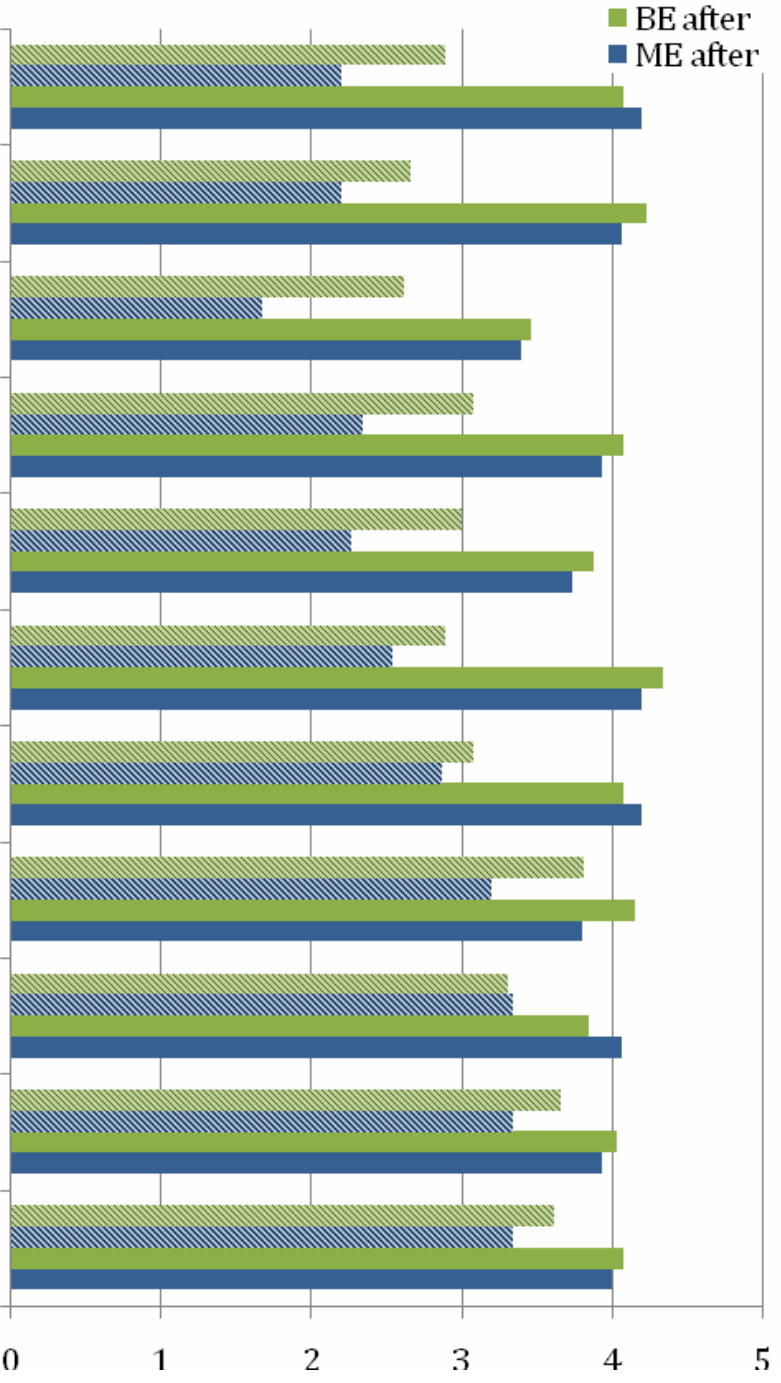

Figure 4: Improvements in the average confidence rating in learning objectives for the skills lab for each major. $\mathrm{N}=30 \mathrm{BE}$ students and $18 \mathrm{ME}$ students.

\section{Conclusions}

Courses that use lecture techniques to implicitly take into account the range of learning styles can be helpful to ensure that all students, from many backgrounds, learn as much of the material as possible. This course goes further and explicitly incorporates learning styles into the discussion section to help students present technical information and communicate in multidisciplinary teams. Students reported that using learning styles to assign groups brought in new and creative ideas. Although some students reported that the range of learning styles in the groups hindered their discussions and made it difficult to come to a consensus, the diversity forced the students to learn how to work with people who have different learning styles. Wilde discovered similar results, “... in the long run teams do better when they are composed of people with the widest possible range of personalities, even though it takes longer for such psychologically diverse teams to achieve smooth communications and good cooperation." 5 
Designing a course to fulfill ABET requirements $3 \mathrm{~d}$ and $3 \mathrm{~g}$ about teamwork and communication and assessing its success can be a challenge. ${ }^{16,17}$ We hope this course can serve as a possible model for instructors faced with this task. This course, the skills lab, and the final project could also be helpful in meeting other ABET program outcome requirements, such as 3a) "an ability to apply knowledge of mathematics, science, and engineering," 3c) "an ability to design a system, component, or process to meet desired needs within realistic constraints such as economic, environmental, social, political, ethical, health and safety, manufacturability, and sustainability," and 3f) "an understanding of professional and ethical responsibility."

One of the strengths of this study is that we were able to track the progress of individual students throughout the course and get their feedback. We were also able to see how the diversity of learning styles played into the group dynamics. However, in order to properly gage the effectiveness of the group-forming technique, we would need to evaluate the performance of groups formed with a variety of learning styles to those formed randomly or by self-selection, which we did not have enough students for. Since this report was primarily meant to be an aide for instructors developing similar courses and the sample size was small, we did not perform a statistical analysis on our results or present the standard deviations.

Using the Felder-Soloman Index of Learning Styles is a well-known and respected method for assessing preferred learning styles, and is relatively simple to explain and easy and free for the students to use. The results of the index provide an indication of an individual's learning preferences, but should not be over-interpreted or used to judge a student's suitability for a certain class or discipline. ${ }^{2}$ Also, it is not meant to incorporate the other dimensions of personality that affect teamwork. ${ }^{18}$ A Meyer-Briggs personality profile could also be incorporated into such a course to enhance the teamwork and leadership aspect. ${ }^{5,6}$

There are a few aspects of the course that we hope to improve upon in future iterations, including survey design and establishing expectations. Some of the multiple choice answers could be interpreted in different ways so that the student's actual intentions could not be determined. For example, "the opposing learning styles makes it difficult to work together effectively and come to agreement" could point to a problem in either communicating ideas (working together effectively), or just evaluating which idea is the best (coming to an agreement), or both. Biases in the survey wording might also skew results. Also, since the survey was blinded, we could not match their perceived competence in a learning objective with their actual grades.

Although we received positive and encouraging feedback from many students, some students did not appreciate the break from a traditional course format (especially the emphasis on peer editing and Bloom's taxonomy) and complained that what they were learning in the skills lab had nothing to do with what they would need in the "real world." Properly establishing expectations of course content and format and the reasoning behind them at the beginning of (and throughout) any course that uses non-traditional teaching techniques is critical to minimizing student backlash and maximizing student engagement. This is likely more true for classes with juniors and seniors that have become accustomed to traditional courses than for an introductory course with freshmen.

Although we are continually looking for ways to improve this course, our observations suggest that this course format could serve as a basis for other group-project based, multidisciplinary courses. We believe that if the students are aware of their own learning style and know how to 
effectively communicate with people of different learning styles, and if they gain experience working in groups with diverse learning styles, then they would be better able to work on multidisciplinary and diverse teams in the future. This would be useful for not only developing students' professional skills, but also meeting ABET program outcome objectives.

\section{Bibliography}

1. R.M. Felder \& L.K. Silverman, "Learning and Teaching Styles in Engineering Education," Journal of Engineering Education, 78(7), 674-681 (1988).

2. Richard M. Felder and Barbara A. Soloman, Index of Learning Styles, <http://www.ncsu.edu/felderpublic/ILSpage.html>, accessed 2009.

3. ABET, Criteria for Accrediting Engineering Programs, Effective for Evaluations During the 2009-2010 Accreditation Cycle. Baltimore, Md.: Engineering Accreditation Commission, Nov. 1, 2008.

$<\mathrm{http} / / /$ www.abet.org/Linked\%20Documents-UPDATE/Criteria\%20and\%20PP/E001\%200910\%20EAC\%20Criteria\%2012-01-08.pdf >.

4. A. Halstead \& L. Martin, "Learning styles: a tool for selecting students for group work," International Journal of Electrical Engineering Education, 39(9), 245-252 (2002).

5. D. Wilde, "Personalities into Teams,” Mechanical Engineering, 2010 Feb; 22-25.

6. R.M. Felder \& R. Brent, "Understanding Student Differences," Journal of Engineering Education, 94(1), 57-72 (2005).

7. R.M. Felder and J.E. Spurlin, "Applications, Reliability, and Validity of the Index of Learning Styles," International Journal of Engineering Education, 21(1), 103-112 (2005).

8. M. Zywno, "A Contribution to Validation of Score Meaning for Felder-Soloman's Index of Learning Styles," Proceedings, 2003 ASEE Annual Conference, American Society for Engineering Education, June 2003.

9. T.A. Litzinger, S.H. Lee, J.C. Wise, and R.M. Felder, "A Study of the Reliability and Validity of the FelderSoloman Index of Learning Styles," Proceedings, 2005 ASEE Annual Conference, American Society for Engineering Education, June 2005.

10. Benjamin S. Bloom. Taxonomy of educational objectives. Allyn and Bacon, Boston, MA. 1984, Pearson Education.

11. Rosati, P., Specific Differences and Similarities in the Learning Preferences of Engineering Students, Session 12c1, Proceedings of the $29^{\text {th }}$ ASEE/IEEE Frontiers in Education Conference, San Juan, Puerto Rico, (1999).

12. Montgomery, S., Addressing Diverse Learning Styles through the Use of Multimedia: Material and Energy Balance, Proceedings of the $25^{\text {th }}$ ASEE/IEEE Frontiers in Education Conference, Atlanta, GA, USA, (1995).

13. Smith, N.G., Bridge, J. \& Clarke, E., An evaluation of students' performance based on their preferred learning styles. In: Z.J. Pudlowski (Ed.), Proceedings of the $3^{\text {rd }}$ UNESCO International Centre for Engineering Education (UICEE) Global Congress on Engineering Education, Glasgow, Scotland, UK, pp. 284-287, (2002).

14. Kuri, N.P. \& Truzzi, O.M.S., Learning Styles of Freshmen Engineering Students, Proceedings of the 2002 International Conference on Engineering Education (ICEE), Manchester, UK, (2002). 
15. Livesay, G., Dee, K., Felder, R., Hites, L., Nauman, E. \& O'Neal, E., Statistical Evaluation of the Index of Learning Styles, Session 2430, 2002 ASEE Annual Conference and Exposition, Montreal, Quebec, Canada, (2002).

16. D. Kim \& H. Gurocak, Design Panel: A Tool for Assessment in Design Courses, Proceedings of 2007 ASEE Annual Conference and Exposition, Honolulu, Hawaii, USA, (2003).

17. L.J. Shuman, M. Besterfield-Sacre, \& J. McGourty, "The ABET 'Professional Skills' - Can they be Taught? Can they be Assessed?", Journal of Engineering Education, 94(1), 2005, pp. 41 - 55.

18. J.E. Sharp, "A Resource for Teaching a Learning Styles/Teamwork Module with the Soloman-Felder Index of Learning Styles." Proceedings of the Frontiers in Education 2003 33rd Annual Conference, November 5-8, 2003, 5 pp, Boulder, CO. 